\title{
Maternal and Fetal Outcomes of 179 Traumatised Pregnants in Teritary Referral Center
}

\author{
İsmet Alkış' ${ }^{1}$, Sevdegül Karadaş², Erbil Karaman ${ }^{3 *}$, İsmail Gülşen², Reşit Öncü², \\ Numan Cim ${ }^{1}$, Recep Dursun ${ }^{4}$ \\ ${ }^{1}$ Department of Obstetric and Gynecology, Yüzüncü Yıl University, Van, Turkey \\ ${ }^{2}$ Department of Emergency Medicine, Medical Faculty, Yüzüncü Yıl University, Van, Turkey \\ ${ }^{3}$ Department of Obstetric and Gynecology, Erciş State Hospital, Van, Turkey \\ ${ }^{4}$ Department of Emergency Medicine, Medical Faculty, Dicle University, Diyarbakır, Turkey \\ Email: ${ }^{*}$ erbil84@gmail.com
}

Received 28 September 2014; revised 25 October 2014; accepted 18 November 2014

Academic Editor: Moon Whan Im, Inha University School of Medicine, South Korea

Copyright (C) 2014 by authors and Scientific Research Publishing Inc.

This work is licensed under the Creative Commons Attribution International License (CC BY). http://creativecommons.org/licenses/by/4.0/

(c) (i) Open Access

\section{Abstract}

Objective: The aim of this study was to evaluate the clinical characteristics, maternal and fetal outcomes of trauma in pregnants. Methods: This is a retrospective analysis of all traumatised pregnants who admitted to Yüzüncü Yıl University teritary referral hospital from June 2010 and December 2012. One hundred seventy-nine pregnants in whom referred for trauma analysed for the data about mechanism of trauma, demographic and obstetric parameters on admission, diagnostic and surgical procedures performed, maternal and fetal outcomes. The SAS statistical package version 9.2 was used in data analysis. Results: Overall, the medical records of 179 patients were reached and included in the study. The mean age was $27.5 \pm 5.8$. Gestational age ranged from 6 to 39 weeks (mean, 26.2 weeks), with most trauma $(49.1 \%)$ being in the third trimester. Road trrafic accident (RTA) was the main mechanism of trauma (41.5\%) followed by falls $(26.4 \%)$. Trauma due to animal recoil was seen in three patients. The most injured body area was extremity (34.2\%). Traumatised pregnants resulted in metarnal (4 cases) and fetal (16 cases) loss. Most of the fetal loss $(\mathbf{4 9 . 1 \% )}$ was seen third trimester, with the main cause detected as placental abruption (8 cases). When compared the complicated pregnancy according to trauma site, abdominal trauma $(33.3 \%)$ was significantly related to complication in pregnancy than non-abdominal trauma $(21.9 \%)(p=0.014)$. Conclusions: Trauma in pregnancy carries risks for both mother and baby. Trauma to abdominal region and trauma in second or third trimester pregnancy is associated with significantly higher maternal and fetal complications.

\footnotetext{
${ }^{*}$ Corresponding author.
} 


\section{Keywords}

\section{Pregnancy, Trauma, Maternal Mortality, Fetal Outcomes}

\section{Introduction}

Maternal injuries constitute risk for both mother and fetus [1]. Trauma during pregnancy is one of the leading cause of non-obstetric maternal mortality. It is estimated that trauma complicates $6 \%-7 \%$ of all pregnancies [2]. Although the management of traumatised preganants is challenging due to the anatomical and physiological changes during pregnancy, the principles and priorities for care are the same as non-pregnants traumatised women [3] [4]. The increased risk of obstetric complications such as abortion, premature rupture of membranes, preterm delivery, placental detachment, stillbirth and maternal death have been associated with trauma during pregnancy [5]. In a cohort study, it is reported that severely injured pregnants were at a 17-fold increased risk for abruption and a 20-fold increase risk for fetal death than nonseverly injured pregnants [6].

The mechanisms and etiologies of trauma during pregnancy varies between populations depending on cultural and geopolitical conditions. Some studies have suggested that the lack of a seat belt or other restraints increases the risk of both maternal [6] and fetal [7] morbidity and death. The causes of maternal trauma during pregnancy is almost similar to that of general population. Most published studies documanted that the common causes of trauma in pregnancy are road traffic accident, falls, physical assault, burns, gunshot, and firearms [5] [8].

It is reported that the only $0.3 \%$ to $0.4 \%$ of pregnant women require hospitalisation due to trauma so the experience of physician for that condition is small [9] [10]. In the view of these data, the objective of the present report was to disccuss the clinical characteristics, pattern of presentations and fetal-maternal outcomes of trauma during pregnancy in a teritary referral center.

\section{Materials and Methods}

After obtained the institutional review board approval, we conducted a retrospective analysis of pregnants who admitted to emergency department of Yüzücü Y1l University medical faculty between June 2010 and December 2012 with diagnosis of local or general body trauma. The inclusion criteria consisted of all pregnant patients requiring hospital admission following injury. The medical records of these patients served as the source of data. Our university serves a population of 1 million and is one of the major university teaching hospital in eastern region of Turkey.

Information such as demographic and obstetric data, etiology and mechanism of injury, trauma score parameters, anatomical site of injury, complications related to trauma, maternal and perinatal outcome were all extracted from the patient's recorded case notes. All patients were received firstly by emergency unit and a multidisciplinary team evaluated the patients including emergency physicians, surgeons, anesthesists, radiologists and others as demanded. As a policy of our hospital, any women that admmitted to emergency department has undergone suspicion of evalaution for pregnancy, and in the case of pregnancy, after the initial evaluation and stabilization in the emergency department, the obstetrics team was consulted and involved in the immediate and hospital care. The condition of the women was evaluated, observed, and monitored obstetrically, based on published guidelines [11].

The treatment modalities including obstetric/nonobstetric intervention, supportive therapies (hospitalisation, analgesics, steroids, antibiotics, blood product replacement) were also analysed. The pregnants who were discharge with normal developing pregnancy were examined routinely in our obstetric clinic and in whom lost follow up, personal interview with telephone communication served as additional data.

\section{Statistical Analysis}

Statistical analysis was performed with the SAS statistical package version 9.2. Descriptive statistics for constant variables were defined as mean \pm standard deviation (SD), minimum and maximum values, and categorical variables were defined as number (n) and percent (\%). For all statistical analysis, a $P<0.05$ was considered significant. Fisher exact and qui-square test was used to determine whether there was a statistically significant difference between groups in terms of categorical variables. 


\section{Results}

During the 30-month study period, 179 patients were included in the study. The pregnants age was between 15 and 44 years. The mean age was $27.5 \pm 5.8$. The mean gestational age was 26.2 ranging from 6 to 39 weeks at the time of injury. About $18.6 \%$ of injuries occurred during the 1 st trimester, $32.2 \%$ in the 2nd trimester, and 49.1\% in the 3rd trimester as shown in Table 1. 113 patients were multiparae (63.2\%) and 66 patients were primigravidae (36.8\%). The mean Glascow coma score (GKS) was 14.8 ranged between 6 to 15. The demographic and clinical data of patients are listed in Table 1.

When the subjects were analysed according to mechanism of trauma, road trraffic accident (RTA) was the most common cause of injury with number of 74 (41.5\%), whereas falls, physical assaults and burns accounted for injuries in 47 (26.4\%), 38 (21.3\%) and 8 (4.4\%) of patients, respectively as shown in Table 2. Hovewer there was three patients with trauma due to animal recoil which is related to the local, traditional daily work in our city which has low economical development in our country. The RTA and assaults were seen in all the trimester whereas the falls and animal recoil occured more often in second and third trimester. When the patients were evaluated according to the trauma related body injured area, 24 patients (13.4\%) had abdominal trauma, whereas the extremitiy was the most common injured body area (61, 34.2\%).

The overall maternal death was seen in four patiets (2.2\%) in these 179 cases. All of these cases had RTA and had general body trauma with multiple organ injury. One patient was in first trimester, the other in second

Table 1. Demographic data of traumatised pregnant.

\begin{tabular}{cc}
\hline Variable & Value (n: 179, all patients) \\
\hline Age (years) & $27.5(15-44)$ \\
Gestational age (weeks) & $33(18.6 \%)$ \\
First trimester (n, \%) & $57(32.2 \%)$ \\
Second trimester (n, \%) & $87(49.1 \%)$ \\
Third trimester (n, \%) & $2.8 \pm 2.05$ \\
Gravida & $1.7 \pm 1.9$ \\
Parity & \\
Vital signs on admission & $112.3 \pm 11.8$ \\
Systolic blood pressure (mmHg) & $75.4 \pm 7.9$ \\
Diastolic blood pressure (mmHg) & $14.8 \pm 1.1$ \\
Glasgow coma scale & $11.4 \pm 1.8$ \\
Hemoglobin level (gr/dl) & $34.4 \pm 4.9$ \\
Hematocrite level (\%) &
\end{tabular}

Table 2. Mechanisms of trauma and body area injured.

\begin{tabular}{cc}
\hline Variable & Number (\%) of Pregnants \\
\hline Type of trauma & \\
Road accident & $74(41.5 \%)$ \\
Falls & $47(26.4 \%)$ \\
Electrical schock & $4(2.2 \%)$ \\
Physical assault & $38(21.3 \%)$ \\
Burn & $8(4.4 \%)$ \\
Animal recoil & $3(1.6 \%)$ \\
Other & $4(2.2 \%)$ \\
Body area injured & \\
Abdomen & $24(13.4 \%)$ \\
Thorax & $10(5.5 \%)$ \\
Head-neck & $37(20.6 \%)$ \\
Pelvis & $13(7.2 \%)$ \\
Extremity & $61(34.2 \%)$ \\
Vertebra & $25(14 \%)$ \\
\hline
\end{tabular}


trimester and the two others were in third trimester. Two patient's pregnancies ended with spontaneous abortion. One of these patients with 33 weeks pregnancy had peri-mortem cesarean section but the baby with 1900 gr survived for just three days. The other patient in 36 weeks of pregnancy admitted with intrauterin death fetus to emergency unit. The overall fetal death rate was 8.9\% (in 16 cases). The etiology of trauma in fetal loss was a traffic accident in 8 of the fetal loss cases, falls were detected in 4, physical assault was detected in 2, animal recoil was detected in 2 pregnants with hit in the abdomen with animal feet.

There was preterm delivery in 12 patients (6.7\%). Abruptio placenta was seen in 8 patients (4.4\%). Fall was the mechanism of injury observed in 4 patients who presented with abruptio placenta and in other three patients, RTA was mechanism of injury in which with multiple lower extremity fractures. The other pregnant with abruptio placenta was due to animal recoil to lower abdomen with 32 weeks of pregnancy. Uterine rupture was seen in two patients. One of them was victim of intentional penetrating trauma with knife and the other was due to road trafic collision.

When we analysed the fetal loss according to trimester, $18.6 \%, 32.2 \%$ and $49.1 \%$ of fetal loss was seen in first trimester, second and third trimester, respectively. It is seen that about half of the fetal loss was in third trimester.

In Table 3, we compared the results of abdominal trauma and non-abmoninal injury. Complicated pregnancy involved any of the vaginal bleeding, hospitalisation for abortus imminens, spontaneous abortion, stillbirth, intrauterin fetal death or neonatal death. Pregnancy outcome was complicated in 42 (23.4\%) and uncomplicated in 137 (76.6\%). It was seen that 33.3\% of abdominal trauma ended with complicated pregnancy whereas, $21.9 \%$ of nonabdominal injury resulted with complicated pregnancy. There was a statistical significant difference between the two groups $(P=0.014)$ (Table 4$)$.

\section{Discussion}

Trauma during pregnancy is reported to be seen in $6 \%-7 \%$ of all pregnancies [2]. It is one of the leading cause of nonobstetrical death for pregnant women. Because of active participation of pregnant women to daily life is increasing, we would be faced more with trauma during pregnancy [10]. The mechanism of trauma in pregnants is globally same but the proportion of cases involved in each of them varies from place to place. Most published data has shown that the most common cause of trauma is an trrafic accident, followed by falls, poundings and burns [12] [13]. In our present case series, the road accident was most common cause as consistent with literature followed by falls, electrical schock, physical assaults as shown in Table 2. A previous study published by Karadaş et al. [14] from our university hospital which anlaysed 139 cases of traumatised pregnants between years of 2006 and 2009 showed that the most common cause of trauma as falls during daily activities as 43.9\%, despite to this data RTA was the leading cause of trauma as $41.5 \%$ in our study. This statistical changes over years may be explained by the economical development of place, joining of more automobiles to trrafic and changes in demographics of population. The involvement of animal recoil was 3 in all trauma patients and this was not surprising as livestock is a common mode of daily bread in eastern part of our country.

Table 3. Pregnancy outcome by abdominal trauma.

\begin{tabular}{ccc}
\hline Abdominal trauma & Non-abdominal trauma & Total \\
\hline $\mathrm{n}(\%)$ & $\mathrm{n}(\%)$ & $34(21.9)$ \\
Complicated pregnancy $^{*} 42(23.4)$ & $8(33.3)$ & $121(78.1)$ \\
Uncomplicated pregnancy $137(76.6)$ & $16(67)$ & $24(100)$
\end{tabular}

* Indicates spontaneous abortion, stillbirth, fetal death in utero, or neonatal death occurred. Fisher exact test test: $P<0.014$.

Table 4. Maternal and fetal complications (obstetric) related to trauma.

\begin{tabular}{ccc}
\hline Complications & Number of patients & (\%) \\
\hline Maternal death & 4 & 2.2 \\
Preterm labour & 12 & 6.7 \\
Apruptio placenta & 8 & 4.4 \\
Abortion/Stillbirth & 16 & 8.9 \\
Uterine rupture & 2 & 1.1 \\
\hline
\end{tabular}


Tinker et al. reported that the most common cause of trauma as falls (51.6\%) followed by accident and they implicated that trauma was most commonly occured in $2^{\text {nd }}$ trimester in their population based study on epidemiology of maternal injuries during pregnancy [8]. Our findings was not correlated with this as $49.1 \%$ of trauma seen in $3^{\text {rd }}$ trimester. Most of injuries due to falls occured in $2^{\text {nd }}$ and $3^{\text {rd }}$ trimester however the RTA and physical assaults were seen throughout in all trimester which is correlated with the findings of a prospectine analysis of trauma on pregnancy by Biswas et al. [15]. This finding may be explained as the center of gravity is more displaced in $2^{\text {nd }}$ and $3^{\text {rd }}$ trimester due to growing of uterus and weight gain.

The morbidity and mortality of trauma in pregnants depends on the mechanism of injury, gestational age of fetus and severity of the injury [16]. Weiss et al. reported that the risk factor for trauma in pregnancy as young maternal age, drug and alcohol use and domestic violence [1]. Also in a recent study by Luley et al. [17] showed that lack of restraint use in automobile is a increased risk factor for fetal death. In this study we had 4 maternal death, the mean age of the subjects was $31.7 \pm 8.2$. The trauma related maternal mortality $2.2 \%$ was lower than 25.92\% reported by Biswas et al. [15]. In our case series, the maternal mortality was due to haemorrhagic shock caused by RTA and general body trauma with multiple organ injury in all cases. In a study by Rothenberger et al. [18] with 103 cases of trauma during pregnancy investigated haemorrhagic shock in all cases of maternal death.

Trauma is linked with a high rate of fetal loss, the most common cause being detachment of the placenta and maternal mortality. As a results of these, generally, fetal compromise in cases of trauma results mainly from associated hypoxia, hypotension and preterm delivery. Thus direct trauma to fetus is not needed for fetal loss, even a minor trauma contribute the poor fetal outcome [19]. Fsicher et al. [19] found that a first- or secondtrimester minor injury was associated with fetal death and prematurity. Haemorrhage caused by trauma precipitate a reduction in blood flow preferentially in the placenta. Severe fetal suffering may occur even in the absence of clinical signs of shock in the mother, because blood volume undergoes a significant increase in the third trimester [3] [4]. For these reasons, the best treatment for the fetus is the re-establishment of the stability of vital functions of the mother [20]. Fetal injury without maternal involvement is rare. In our study we had 16 cases of fetal loss (8.9\%). Most of the fetal loss was associated with road trrafic accident (8 cases). The causes of fetal loss in our cases were: abruptio placenta (8 cases), direct fetal injury (2 cases), spontaneous abortion (2 cases) and therapotic abortion (2 cases). Direct fetal injury was seen in 2 patients with uterin rupture in which of one was victim of knife attack and the other was road traffic accident in which the mother was ejected from vehicle. Eventhough, the uterin rupture is infrequent complication, its mortality rate nearly $100 \%$ [15].

Moise et al. reported that [4] abdominal trauma usually has more severe consequences at the end of pregnancy especially when the head of fetus is embedded in the pelvis and amniotic fluid decrease in some deggree. In case of abdominal trauma, uterus with its elasticity and space occupying effect within abdomen protect the organs. When we examined the fetal loss according to trimester. We investigated fetal loss was occured mostly in third trimester with $49.1 \%$. Consistent with the data in literature, our study shown that fetal outcomes due to trauma become worse when the pregnancy weeks progress.

The detachment of placenta is an important and challenging issue in case of traumatised patients. Obstetricians always has anxiety and suspicion even in minor trauma to a pregnant. It ussually aggravates the clinical state of mother by adding the intravascular coagulatory effect of abruption. In clinical studies, the patients with normal examination and monitorization findings even in minor trauma are recommended to be followed up for at least 2 - 6 hours. In our study, 8 patients were diagnosed with abruptio placenta. 6 of them were diagnosed at initial assesment in emergency room by obstetrician. The other two pregnants were diagnosed 4 and 10 hours after hospitalisation in emergency department. The abruptio was diagnosed with occurance of abnormal fetal heart rate monitoring in one patient and presence of vaginal bleeding and starting of uterin contraction in the other patient. Lifschultz et al. reported two cases of abruption diagnosed within 48 hour of trauma and the other up to 5 days later [21].

Petrone et al. [22] investigated the abdominal trauma in pregnancy with a larger population than our study. They stated that the penetrating trauma to abdomen has higher maternal and fetal mortality than blunt trauma (7\% vs $2 \%)$. During pregnancy, the uterus gradually becomes an intra-abdominal organ weighing close to $1100 \mathrm{~g}$ and expanding to a total volume of $5 \mathrm{~L}$ at term. So the fetus become more vulnerable to trauma. As a policy and recording data of our emergency unit, abdominal trauma is not divided as blunt or penetrating trauma in recording system so we could reach the data only as abdominal trauma. Therefore, we compared the pregnancy outcomes according to abdominal and nonabdominal trauma in terms of complicated pregnancy such as in presence of any of following spontaneous abortion, stillbirth, fetal death in utero, neonatal death, hospitalisation or 
abruption. Our study showed that there was a statistically significant difference beetwen abdominal and nonabdominal trauma with restpect to complication of pregnancy (33.3\% vs $21.9 \%, P<0.005$ ).

The limitation of our study was that it is a retrospective study. The data was collected from medical records which may have some missing data that may lead to lack of abilitiy to compare the findings. This is an important debate of retrospective observational studies. Another limitation was that it is a hospital-based single center study that may not be a representative of entire population.

In conclusion, trauma in pregnancy remains a challenging issue. The physicians should be aware of the physiological changes of hemodynamic parameters in pregnants. Both mother and fetus should be evaluated in cases of traumatised pregnants. Trauma to abdominal region and in second or third trimester pregnants is associated with significantly higher maternal and fetal complications.

\section{Conflict of Interest}

The authors declare that they have no conflict of interest.

\section{References}

[1] Weiss, H.B., Songer, T.J. and Fabio, A. (2001) Fetal Deaths Related to Maternal İnjury. JAMA, 286, 1863-1868. http://dx.doi.org/10.1001/jama.286.15.1863

[2] Connolly, A.M., Katz, V.L., Bash, K.L., McMahon, M.J. and Hansen, W.F. (1997) Trauma and Pregnancy. American Journal of Perinatology, 14, 331-336. http://dx.doi.org/10.1055/s-2007-994155

[3] Alexander, R.H. and Proctor, R.J., American College of Surgeons (1993) Trauma in Pregnancy. In: Advanced Trauma Life Support Instructor Manual, 283-292.

[4] Moise Jr., K.J. and Belfort, M.A. (1997) Damage Control during Pregnancy. Surgical Oncology Clinics of North America, 77, 839-845.

[5] Esposito, T.J., Gens, D.R., Smith, L.G., Scorpio, R. and Buchman, T. (1991) Trauma during Pregnancy a Review of 79 Cases. Archives of Surgery, 126, 1073-1078. http://dx.doi.org/10.1001/archsurg.1991.01410330027003

[6] Schiff, M.A., Holt, V.L. and Daling, J.R. (2002) Maternal and İnfant Outcomes after İnjury during Pregnancy in Washington State from 1989 to 1997. The Journal of Trauma, 53, 939-945. http://dx.doi.org/10.1097/00005373-200211000-00021

[7] Hyde, L.K., Cook, L.J., Olson, L.M., Weiss, H.B. and Dean, J.M. (2003) Effect of Motor Vehicle Crashes on Adverse Fetal Outcomes. Obstetrics \& Gynecology, 102, 279-286. http://dx.doi.org/10.1016/S0029-7844(03)00518-0

[8] Tinker, S.C., Reefhuis, J., Dellinger, A.M. and Jamieson, D.J. (2010) National Birth Defects Prevention Study. Epidemiology of Maternal Injuries during Pregnancy in a Population-Based Study, 1997-2005. Journal of Women's Health, 19, 2211-2218. http://dx.doi.org/10.1089/jwh.2010.2160

[9] Ali, J., Yeo, A., Gana, T.J., et al. (1997) Predictors of Fetal Mortality in Pregnant Trauma Patients. The Journal of Trauma, 42, 782-785.

[10] Brown, H.L. (2009) Trauma in Pregnancy. Obstetrics \& Gynecology, 114, 147-160. http://dx.doi.org/10.1097/AOG.0b013e3181ab6014

[11] American College of Obstetricians and Gynecologists (1998) Educational Bulletin No. 251: Obstetric Aspects of Trauma Management. Washington DC.

[12] Pearlman, M.D. (1997) Motor Vehicle Crashes, Pregnancy Loss and Pre-Term Labor. International Journal of Gynecology \& Obstetrics, 57, 127-132.

[13] Baker, D.P. (1982) Trauma in Pregnancy. Surgical Oncology Clinics of North America, 62, 313-329.

[14] Karadas, S., Gonullu, H., Oncu, M.R., Kurdoglu, Z. and Canbaz, Y. (2012) Pregnancy and Trauma: Analysis of 139 Cases. Journal of the Turkish German Gynecological Association, 13, 118-122. http://dx.doi.org/10.5152/jtgga.2012.13

[15] Biswas, S.C., Mukhopadhyay, G., Kundu, D., Mukhopadhyay, M., Sen, S. and Biswas, B. (2004) Trauma in Pregnancy: A 5-Year Prospective Analysis of Fetamaternal Outcome in a Tertiary Centre. Journal of Obstetrics and Gynaecology of India, 54, 452-455.

[16] Pearlman, M.D., Tintinalli, J.E. and Lorenz, R.P. (1990) Blunt Trauma during Pregnancy. The New England Journal of Medicine, 323, 1609-1613.

[17] Luley, T., Fitzpatrick, B., Grotegut, C.A., et al. (2013) Perinatal Implications of Motor Vehicle Accident Trauma during Pregnancy: İdentifying Populations at Risk. American Journal of Obstetrics \& Gynecology, 208, 466.e1- 
466.e15.

[18] Rothenberger, D., Quattlebaum, F.W., Perry Jr., J.F., et al. (1978) Blunt Maternal Trauma: A Review of 103 Cases. The Journal of Trauma, 18, 173-179.

[19] Fischer, P.E., Zarzaur, B.L., Fabian, T.C., et al. (2011) Minor Trauma Is an Unrecognized Contributor to Poor Fetal Outcomes: A Populationbased Study of 78,552 Pregnancies. The Journal of Trauma, 71, 90-93. http://dx.doi.org/10.1097/TA.0b013e31821cb600

[20] Kissinger, D.P., Rozycki, G.S., Morris Jr., J.A., et al. (1991) Trauma in Pregnancy: Predicting Pregnancy Outcome. Archives of Surgery, 126, 1079-1086.

[21] Lifschultz, B.D. and Donoghue, E.R. (1991) Fetal Death Following Maternal Trauma: Two Case Reports and Survey of the Literature. Journal of Forencis Sciences, 36, 1740-1744.

[22] Petrone, P., Talving, P., Browder, T., Teixeria, P.G., Fisher, O., Lozronio, A., et al. (2011) Abdominal Injuries in Pregnancy: A 155-Month Study at Two Level 1 Trauma Centers. International Journal of the Care of the Injured, 42, 47-49. http://dx.doi.org/10.1016/j.injury.2010.06.026 
Scientific Research Publishing (SCIRP) is one of the largest Open Access journal publishers. It is currently publishing more than 200 open access, online, peer-reviewed journals covering a wide range of academic disciplines. SCIRP serves the worldwide academic communities and contributes to the progress and application of science with its publication.

Other selected journals from SCIRP are listed as below. Submit your manuscript to us via either submit@scirp.org or Online Submission Portal.
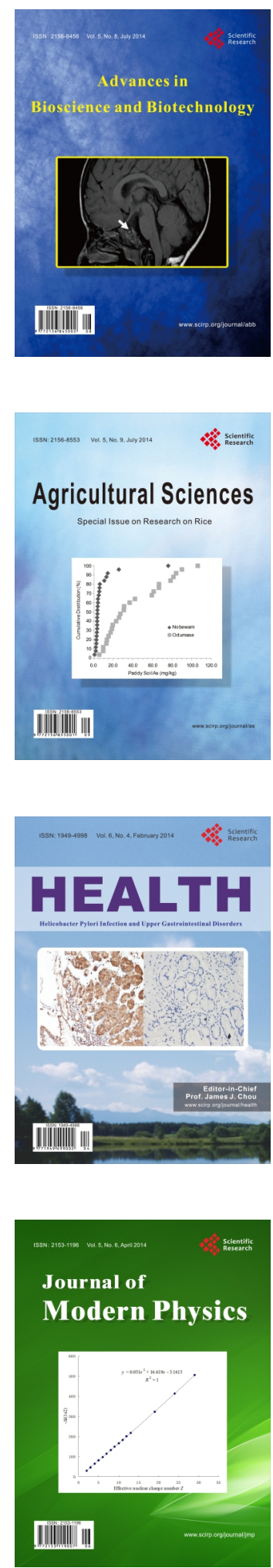
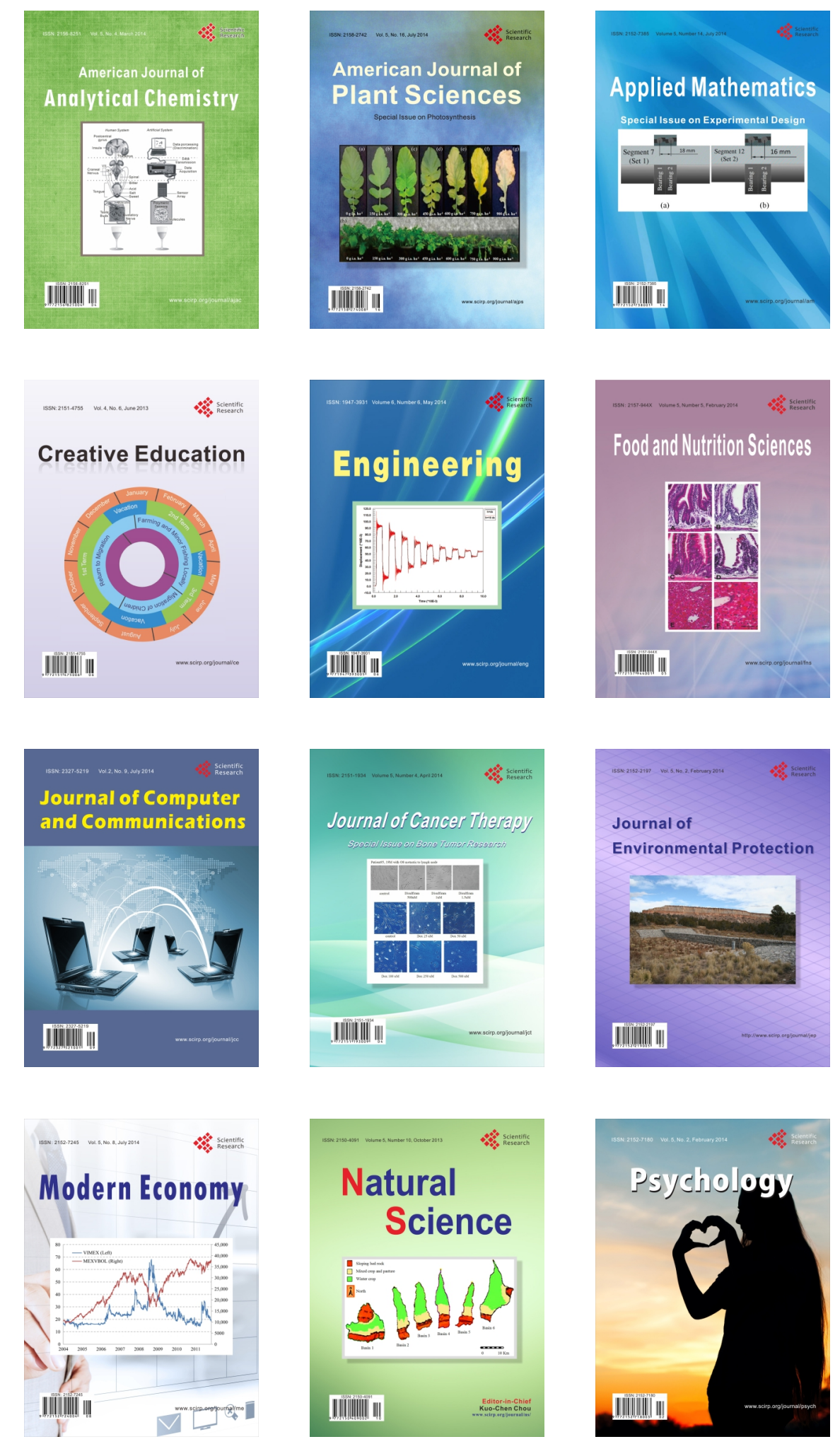